\title{
EXPERIÊNCIA RELIGIOSA EM GRUPOS DE AUTO-AJUDA: O EXEMPLO DE NEURÓTICOS ANÔNIMOS
}

Marcelo Vial Roehe*

RESUMO. O artigo caracteriza o que são os grupos de auto-ajuda, apresenta o programa de recuperação do grupo Neuróticos Anônimos (N/A) e revisa sucintamente o papel da religião na saúde em geral e no psiquismo. A seguir, o trabalho explora o aspecto religioso da pesquisa de Mestrado do autor, sobre a recuperação no grupo de auto-ajuda N/A. Trechos de entrevistas são citados, a fim de exemplificar a discussão. A experiência religiosa manifestada pelos integrantes de N/A entrevistados se mostrou determinante no processo de recuperação, a ponto de vir a confundir-se com este. A experiência religiosa acaba por ser um requisito para a "cura", uma vez que o programa de recuperação do grupo é uma versão terapêutica dos princípios básicos da doutrina judaico-cristã.

Palavras-chave: grupos de auto-ajuda, Neuróticos Anônimos, psicologia da religião.

\section{RELIGIOUS EXPERIENCE IN SELF-HELP GROUPS: THE NEUROTICS ANONYMOUS EXAMPLE}

\begin{abstract}
The article presents the defining characteristics of the self-help groups, describes the recovery program of the Neurotics Anonymous group and briefly revises the role of religion in psychological and general health. The article also explores the religious aspect of the autor's Master degree research, about recovery in Neurotics Anonymous self-help group. Portions of interviews are cited as discussion's examples. The religious experience presented by Neurotics Anonymous' members apeared as a determinant in their process of recovery in a way that makes difficult to distinguish between the two. The religious experience is a requirement for "cure" because the group's recovery program is a therapeutic version of the biblical doctrine basic principles.
\end{abstract}

Key words: self-help groups, Neurotics Anonymous, religion psychology religion.

Este estudo se desenvolve a partir do interesse do autor em saber como se dá o entendimento e o "tratamento" da "neurose" num contexto leigo como o da auto-ajuda.

O objetivo da pesquisa foi investigar como integrantes de Neuróticos Anônimos percebem seu processo de recuperação, a fim de contribuir para uma aproximação entre a Psicologia e grupos de auto-ajuda (GAAs). Pretendeu-se, ainda, apresentar e compreender a vivência dos membros de N/A entrevistados, tornando-a acessível a profissionais de saúde mental, com vistas a facilitar uma maior colaboração entre estes e o grupo e diminuir eventuais preconceitos referentes a GAAs.

Grupos de auto-ajuda (GAAs)

Inicialmente, convém destacar que, de acordo com o processo básico de funcionamento dos GAAs, a denominação mais adequada é a de ajuda mútua (Sanchez Vidal, 1991). O autor propõe uma integração das duas expressões: são grupos de auto-ajuda na medida em que mantêm total autonomia em relação a instituições e profissionais (ou seja, o grupo ajuda a si mesmo); e são grupos de ajuda mútua porque baseiam sua atuação na mutualidade (os participantes ajudam uns aos outros).

A partir dos trabalhos de Borkman (1976), Jacobs e Goodman (1989), Levy (1976) e Rootes e Aanes (1992), reuniram-se mais informações para melhor definir um GAA. Os critérios mais utilizados são os seguintes:

- autogestão - os próprios integrantes encarregam-se de todos os procedimentos necessários para a manutenção do grupo;

- independência de instituições e profissionais de saúde - os GAAs são leigos e autônomos;

- participação voluntária - a frequiência ao grupo é totalmente livre;

* Docente do Curso de Psicologia da URI-Campus Frederico Westphalen/RS. Psicólogo pela UFRGS, Mestre em Psicologia pela PUCRS. 
- nenhum interesse financeiro - os GAAs não visam a lucro; sustentam-se com doações espontâneas dos integrantes;

- dirigidos para um único problema - os grupos têm um foco: alcoolismo, drogadição, problemas emocionais, compulsão alimentar;

- experiências pessoais como principal fonte de ajuda - os GAAs não utilizam conhecimento científico ou literatura especializada; o conhecimento partilhado é experiencial.

Os GAAs proliferaram nos EUA depois da experiência pioneira e positiva dos Alcoólicos Anônimos (grupo criado em 1935, nos EUA).

Para Sanchez Vidal (1991), a primazia dos EUA no desenvolvimento de GAAs deve-se à importância atribuída na sociedade norte-americana às iniciativas da sociedade civil, estimulando que as pessoas se responsabilizem por sua cidadania.

Dumont (1974) associa a origem do programa dos Doze Passos, criado por Alcoólicos Anônimos e utilizado por vários grupos, entre eles N/A, à tradição protestante norte-americana. Exemplos disso são o reconhecimento da pecaminosidade, o modelo confessional e a busca por pureza espiritual. Também a cultura da igualdade, típica dos GAAs, encontra respaldo na sociedade norte-americana, orientada para coesão por identificação grupal, limites bem demarcados entre diferentes grupos e divisões étnicas nas metrópoles (Dumont, 1974).

Além disso, surge um novo senso de igualitarismo, contribuindo, conforme Vattano (1972), para a queda em importância da autoridade e do status tradicional (exemplo é o bordão "power to the people"). Assim, iniciativas com respaldo oficial e credenciais especiais já não são automaticamente consideradas competentes (Back \& Taylor, 1976).

Para Dumont (1974), os GAAs reforçam a idéia de que a distância entre quem ajuda e quem é ajudado não deve ser tão grande quanto pensam os profissionais mais tradicionais.

\section{NEURÓTICOS ANÔNIMOS (N/A)}

N/A foi criado em 3 de fevereiro de 1964, nos EUA, quando Grover B., um integrante dos Alcoólicos Anônimos, adaptou o programa do grupo para problemas emocionais.

No Brasil, o grupo iniciou suas atividades em abril de 1969, em São Paulo. O primeiro grupo gaúcho foi criado em Porto Alegre, no ano de 1975. De Mari, Teich, Nogueira, Camargos e Pimentel (1999) informam a existência de 450 grupos de N/A no Brasil.

O autor observou algumas reuniões de N/A, em Porto Alegre/RS. Os encontros duram cerca de duas horas. Os participantes colocam-se, preferencialmente, em círculo. Cada grupo tem um coordenador, geralmente um integrante antigo de N/A. Não são permitidos diálogos e apartes; os integrantes que pedem a palavra ou que são convidados a dar o seu depoimento podem fazê-lo por um período de até 10 minutos. No depoimento, a pessoa costuma falar sobre os motivos que a levaram ao grupo, sua situação atual ou experiências com o programa. Os integrantes de N/A que atingiram uma situação pessoal confortável relatam suas experiências de forma a demonstrar a eficácia do programa aos demais, que ainda buscam progressos. Um dos livretos do grupo informa que, apesar de não haver diálogo, “(...) o que se verifica, na realidade, é uma permuta de experiências e identificação de problemas semelhantes, indiretamente proporcionando as respostas que possam estar sendo procuradas" (Neuróticos Anônimos, livreto, s/d).

A principal referência teórica de N/A é o livro As Leis da Doença Mental e Emocional (1996), conhecido entre os membros do grupo como livro vermelho. Esse trabalho consiste numa coletânea de artigos publicados no Journal of Mental Health (EUA), entre 1965 e 1970. Os textos - 30 mais o prefácio - foram escritos, quase todos, na primeira pessoa do plural, em nome de N/A, com exceção de quatro cujos autores são indicados: dois textos de Grover B., um de um psiquiatra e um de um padre. Além disso, o grupo tem publicado alguns livretos e folhetos e um Boletim Informativo mensal.

Para N/A, neurótica é “(...) qualquer pessoa cujas emoções descontroladas interferem em seu comportamento, de qualquer forma e em qualquer grau, segundo ela mesma o reconhece" (Neuróticos Anônimos, folheto, s/d).

Conforme o entendimento de N/A (1969/1996), existem oito leis que definem a doença mental e emocional:

1) uma única doença, uma coisa só;

2) doença espiritual;

3) sempre a mesma em todas as pessoas, variando apenas nos detalhes superficiais;

4) caracterizada por sintomas penosos, não sendo sempre os mesmos, porém, os que se manifestam;

5) progressiva se não for tratada;

6) de tratamento imediatamente aplicável;

7) causada pelo egoísmo inato, que impede a aquisição da capacidade de amar; 
8) curada pela eliminação do egoísmo e aquisição da capacidade de amar.

Como o próprio grupo reconhece, a idéia de doença espiritual pode gerar uma compreensão errônea, sobrenatural, da neurose. N/A propõe a seguinte definição para espiritual: "Relativo a pensamentos e emoções" (Neuróticos Anônimos, 1966/1996, p. 13). E acrescenta: “(...) 'espírito’ está sendo aí considerado a soma das emoções, pensamentos, atitudes, crenças, modo de sentir, tudo, enfim, que leva o ser humano a agir da maneira que o faz" (Neuróticos Anônimos, 1966/1996, p. 13).

Segundo N/A, a neurose é doença espiritual na medida em que não há comprovação médica de problemas físicos ou mentais. E se é doença espiritual, pode ser curada com ajuda espiritual, por meio da crença num Poder Superior. Nas palavras de N/A:

Para a pessoa doente é unicamente necessário que ela creia nesse Poder, que poderá conceber como queira. Poderá concebê-Lo como sendo a força da gravidade, por exemplo, ou o movimento dos átomos, a evolução, o amor entre os seres humanos, qualquer coisa enfim, não importa qual seja. É preciso apenas, como já dissemos, que admita a existência desse Poder, isto é, a existência de Algo superior a si mesma. Essa crença irá ajudá-la a eliminar o egocentrismo (tão acentuado nos doentes emocionais), a fim de que a pessoa possa vir a se tornar um ser humano no exato sentido da palavra. É dessa forma que podemos sair de nós mesmos (Neuróticos Anônimos, 1966/1996, p. 15-16).

O grupo chama esse Poder Superior de Deus, mas com a ressalva: “(...) segundo a concepção de cada um” (Neuróticos Anônimos, 1966/1996, p.15).

\section{RELIGIÃO, PSICOLOGIA E SAÚDE}

Os termos religião, religiosidade e espiritualidade costumam ser utilizados como sinônimos em estudos empíricos (Miller \& Thorensen, 2003). A diferenciação apresentada por Miller e Thorensen (2003) é que o termo espiritualidade é mais amplo do que religiosidade e religião; estas dizem respeito a entidades sociais ou instituições caracterizadas por crenças e práticas específicas, normas para quem deseja se tornar um integrante $\mathrm{e}$ modos de organização social, ao passo que espiritualidade se refere aos aspectos não-materiais da vida, àqueles que não são comumente percebidos pelos sentidos. A espiritualidade é entendida como um princípio ou qualidade vital que dá vida ou energia aos constituintes materiais do homem (Miller \& Thorensen, 2003). Sendo assim, pode-se dizer que a religião é a formalização social da espiritualidade. As informações a seguir preservam o termo utilizado pelos autores mencionados.

A pesquisa contemporânea indica uma influência positiva da religião sobre a saúde (Argyle, 1993; Hill, 1999; Larson, 1992; McCullough, 1995; Miller e Thorensen, 2003; Paiva, 1998). Efeitos negativos, entretanto, são também observados (Hill, 1999; Larson, 1992; Paloutzian, 1996). Bergin (1988, 1991) afirma que os estudos a respeito da relação entre religião e saúde mental são ambíguos e inconclusos. $\mathrm{O}$ autor acredita que a religiosidade pode ter custos e benefícios para o psiquismo, dependendo de como ela atua na vida do indivíduo. Paloutzian (1996) sustenta posição similar, concluindo que as pesquisas sobre o tema sugerem que como a pessoa é religiosa é mais importante do que se ela é religiosa. Numa visão geral, os efeitos positivos da religião sobre a saúde são bem mais freqüentes do que os negativos (Larson, 1992; Paiva, 1998).

A revisão de Hill (1999) aponta que a prática religiosa é preditor negativo de drogadição e de sexualidade pré e extramarital, é preditor positivo de estabilidade matrimonial e familiar, pode contribuir para abuso infantil e relacionar-se com preconceito e discriminação.

Paiva (1998) informa sobre estudos que apontam diversas formas de bem-estar físico que acompanham a religiosidade, como longevidade e menor taxa de suicídios, menor incidência de distúrbios cardíacos, cirrose hepática, câncer cervical e tuberculose.

Observando com cautela os resultados de alguns estudos, Argyle (1993) escreve que a religiosidade pode influenciar positivamente os comportamentos de ajuda e a preocupação para com os outros.

Para McCullough (1995), a pesquisa sobre prática religiosa pode ser útil no que diz respeito a como ela promove melhor relacionamento interpessoal na família, na comunidade e na própria Igreja, uma vez que compreensão e reconciliação fazem parte do trabalho da Igreja, num mundo caracterizado por divisões entre as pessoas.

Bergin (1988) salienta o papel compensador da religião em situações de dificuldade. A experiência religiosa compensa dificuldades vitais de tal modo que a pessoa pode atingir um nível de "ajustamento" além do que seria esperado.

Paiva (1998) destaca a relevância da religião como recurso para o enfrentamento de circunstâncias 
estressoras. A religião, ao propor maneiras de se compreenderem os acontecimentos, influencia diretamente as avaliações e atitudes de seus adeptos frente ao estressor. Uma pessoa pode, por exemplo, interpretar o evento estressor como sendo um castigo de Deus e, por isso, aumentar a freqüência de suas orações. A religião atua também preventivamente, uma vez que atividades que podem gerar estresse, como uso de drogas, tornam-se menos prováveis na vida de alguém religiosamente comprometido.

Paiva (1998) comenta a revisão de Pargament no tocante a estudos com pacientes crônicos necessitados de diálise, doentes terminais e pacientes com câncer avançado nos quais a religiosidade aparece associada com maior sociabilidade, maior docilidade ao tratamento, menor medo da morte, menor perturbação do sono, menos dor e maior auto-estima. Outros efeitos, de "índole espiritual", têm sido associados ao enfrentamento religioso, como intimidade e identidade, conforto e desafio de crescimento, expressão ou controle das emoções e esperança revolucionária ou escatológica (Paiva, 1998).

Tentando compreender a religião como fenômeno psicológico, Seminério (1998) opta pelo estudo dos determinismos psicológicos, dentre os quais se destaca a "visão antecipatória" que o ser humano tem da própria finitude, a qual constitui sua "angústia básica".

O ponto de partida de Seminério (1998) para o entendimento da religião como fenômeno psicológico é a idéia de intolerância à ambigüidade de Brunswick. Sempre que uma dúvida está presente, o ser humano gera hipóteses, em acordo com suas emoções e convicções, que venham a mitigá-la. As crenças originadas desse processo atuam como "verdades existenciais" que garantem equilíbrio pessoal, independentemente de sua validade "objetiva". Assim considerada, a crença religiosa pode desempenhar uma importante função de defesa, uma tentativa de solução para a ambigüidade, de modo a atribuir um significado à existência (Seminério, 1998).

Pensando na especificidade da religião como alternativa para o enfrentamento de situações estressoras, Pargament (1990; citado em Paiva, 1998) propõe que

Parte do poder singular da religião pode residir em sua capacidade de responder a tão numerosas necessidades de maneiras tão diversas. O caráter abstrato, simbólico e misterioso da maioria das tradições religiosas pode, por vezes, frustrar seus adeptos. Contudo são exatamente essas qualidades que permitem às religiões adaptarem-se às mudanças dos tempos, das circunstâncias e das necessidades (p. 205 do original).

\section{EXPERIÊNCIA RELIGIOSA EM N/A}

Seis integrantes de N/A em Porto Alegre (RS) foram entrevistados sobre seu processo de recuperação, para pesquisa relativa à Dissertação de Mestrado do autor (Roehe, 2000). Foram convidadas para participar do estudo pessoas que se consideravam recuperadas do(s) problema(s) que motivou(aram) sua adesão ao grupo, a fim de que se pudesse obter um relato que abrangesse todo o percurso da recuperação. Essas pessoas ainda estão em N/A porque o grupo, seguindo o modelo de Alcoólicos Anônimos, considera que a recuperação nunca é definitiva, sempre se está em recuperação, e o incentivo aos iniciantes no grupo faz parte do programa.

A informação de caráter religioso apareceu de modo substancial na maioria das entrevistas e é esse aspecto da pesquisa que é explorado na seqüência do artigo. Opta-se pelo termo religião e por termos derivados porque, como se mostrará em seguida, a experiência dos entrevistados, assim como o programa de N/A, está claramente vinculada aos preceitos do cristianismo, e o próprio N/A como instituição é um determinante do relato dos entrevistados.

Entre os problemas pessoais que motivaram os informantes da pesquisa a procurar N/A estão viuvez, alcoolismo do cônjuge, problemas psiquiátricos do cônjuge e história de problemas emocionais como depressão, confusão mental, angústia, insegurança, retraimento social, entre outros relatados nas entrevistas. Sendo assim, as dificuldades emocionais e a conseqüente busca por auxílio dessas pessoas em nada diferem de situações comumente encontradas pelos psicólogos clínicos em seu ambiente profissional. Com essa afirmação, quer-se ressaltar que a trajetória dos entrevistados não constitui um caso extraordinário, que tenha determinado uma opção terapêutica esdrúxula.

Todas as pessoas entrevistadas afirmaram ter prática religiosa. A trajetória religiosa de 4 dos 6 entrevistados é claramente marcada pela participação no grupo. Dois deles, depois de entrar em N/A, retomaram a prática religiosa, que haviam abandonado. Um tornou-se "católico fervoroso", após ingressar no grupo. E o outro desenvolveu uma nova religiosidade, menos apegada à prática formal. Quanto aos dois entrevistados restantes, um mantém participação religiosa desde antes de conhecer N/A e foi em atividades de igreja que conheceu a pessoa que lhe indicou o grupo; o outro, também com prática 
anterior à chegada em N/A, refere ter vivenciado uma "obsessão religiosa", tendo freqüentado uma "casa espírita", apesar de ser católico.

$\mathrm{O}$ estudo não ficou restrito à experiência relatada pelos informantes. N/A oferece um programa de recuperação que abrange, além da proposta apresentada acima, uma adaptação dos Doze Passos (vide Anexo), originalmente elaborados por Alcoólicos Anônimos, grupo criado em 1935. Os passos são as ações que o integrante deve realizar, a fim de atingir a recuperação, a cura. As freqüentes referências dos entrevistados aos entendimentos, ações e jargão presentes no programa de N/A conduziram a pesquisa, também, a uma análise desse programa, gerando como que um debate entre os relatos e a proposta "terapêutica" do grupo.

Perguntado a respeito das transformações que observou em si mesmo ao longo da participação em N/A, A. diz:

(...) a primeira transformação que eu senti é o seguinte: eu diminuí o meu interesse pelo dinheiro, pelos bens materiais, dando mais valor ao espiritual. Eu me tornei religioso (...) eu não era católico, não digo que odiasse, mas não era muito fanático da religião católica e hoje eu sou católico praticante fervoroso (...) eu sinto que Deus me deu uma missão (...) ele me dá forças e eu levo essa missão adiante, dá através do N/A.

O programa de recuperação de N/A apresenta ensinamentos básicos da doutrina cristã como sendo um caminho para a saúde emocional. Compreender a doença emocional como “(...) egoísmo inato que impede a aquisição da capacidade de amar" (Neuróticos Anônimos, 1969/1996, p. 1) e propor que a cura exige "Acreditar que um poder superior a nós mesmos poderia devolver-nos à sanidade" ( $2^{\circ}$ passo) e, portanto, que é necessário entregar a vontade e a vida aos cuidados de Deus - o Poder Superior - , na forma em que $\mathrm{O}$ concebemos ( $3^{\circ}$ passo), é recolocar, na forma de metas de saúde psicológica, os dois principais mandamentos cristãos (Mateus, 22: 37-40): reconhecimento de Deus como poder superior e objetivo primeiro do amor humano e amor aos outros como prova de amor a Deus e valorização dos demais (conduta não egocêntrica, conforme N/A).

$\mathrm{O}$ programa sustenta que "quanto mais perto estivermos das pessoas, mais perto de Deus nós estaremos" (1996/1969, p. 98). Na Primeira Epístola de São João encontra-se: “(...) quem não ama seu irmão, a quem vê, a Deus, a quem não vê, não poderá amar" (1 João, 4: 20).
O percurso pessoal relatado pelos informantes da pesquisa demonstrou a interdependência entre recuperação e religiosidade, como ilustram as seguintes passagens de entrevistas:

(...) eu era doente porque eu não via um Poder Superior a mim, eu era o centro de tudo... se eu fosse procurar um Poder Superior, eu era esse Poder Superior (...) (N.).

(...) tamanha era a minha decadência emocional que eu tentei contra minha vida três vezes... e, graças ao Poder Superior, falhou (...) eu não via outra saída... era só a morte que ia dar jeito em mim, mas creia ou não creia, existe um poder que rege tudo, né? E esse poder me salvou, com a ajuda do programa de N/A. (E.).

Quando eu entrei no N/A... entrei aqui de mal com Deus, inclusive o meu primeiro depoimento foi esse: 'olha, eu me sinto morta e esse Deus não me olha, esse Deus não me ressuscita, esse Deus não me dá vida... esse Deus não faz nada por mim'. E justamente com o programa eu fui melhorando o meu contato com esse Poder Superior, eu fui concebendo... interiormente, esse Poder Superior... aí, no momento que eu fiz o primeiro $5^{\circ}$ passo, eu senti necessidade de me aproximar novamente da Igreja, porque uma das reparações de dano que eu tive que fazer, eu tive que fazer com uma pessoa já falecida (...) (R.).

Este último relato retrata a integração da fé religiosa com a busca de bem-estar emocional, assim como a retomada da participação religiosa dentro da perspectiva inaugurada em N/A. A prática religiosa formal havia sido abandonada, pois $\mathrm{R}$. esperava que sua fé lhe propiciasse bem-estar. Uma vez em N/A, a obtenção de bem-estar é associada à nova concepção de Deus - Poder Superior -, e a realização dos passos oferece a oportunidade de reconciliação com a religiosidade formal.

Outro exemplo alude ao relato de M., no qual ela menciona o sentimento de estar "sendo útil de novo", ao perceber que pode contribuir para o bem-estar dos outros. M. diz:

(...) eu acho que eu preciso fortificar a minha fé, porque tem muita gente que tá precisando da minha fé, porque quando eu falo... no meu grupo, eu sinto que as pessoas recebem aquilo, porque agora eu já tô noutra fase... a 
minha vida está melhorando (...) então eles gostam (...).

M. coloca fé e bem-estar como realizações interdependentes. Primeiro, fé para atingir bem-estar pessoal; depois, reforço da fé, de modo que o bemestar pessoal implique o bem-estar dos demais, ou seja, a concretização da dinâmica interpessoal de base religiosa, que atua em N/A (Roehe, 2000).

Mais uma ilustração do elo entre religiosidade e saúde emocional, instaurado em N/A, é oferecida por N. :

(...) a minha ignorância espiritual também melhorou... Antes eu achava que espiritualidade era um espírito que entrava dentro de mim, me daria coisas boas, Deus ia fazer um milagre comigo, ia me curar, né, então essa ignorância acabou, eu tô sendo mais adulto, não tão criancinha como eu era, tão fantasioso, isso o N/A tudo que me deu, essa ferramenta, essa força... que tá construindo a minha vida....

Esse depoimento demonstra que a mudança de entendimento a respeito da "espiritualidade" derivou para um pensamento mais realista e estimulante da iniciativa pessoal na busca de bem-estar (vide as referências a "ferramenta" e construção da vida).

Analisando os Doze Passos como terapêutica para o alcoolismo, Pfeffer (1958, citado em Martins, 1979) escreve que o $2^{\circ}$ e o $3^{\circ}$ passos propiciam o abandono da onipotência das idéias, procedimento defensivo comum nos alcoolistas, e a aceitação de um personagem paterno protetor.

Em N/A, que trabalha com uma adaptação dos Doze Passos de Alcoólicos Anônimos, verifica-se que um processo análogo tem lugar. A maioria dos entrevistados menciona a transição de um modo de ser superestimado para uma postura mais humilde, menos autocêntrica.

(...) eu acho que eu não tenho humildade suficiente ainda... eu preciso me lapidar nesse ponto, eu acho que eu sou um pouco orgulhosa (...) principalmente em 2 anos que estou em N/A (...) as minhas emoções já não são tão primárias... eu procuro falar mais baixo em casa, eu falava muito alto e sempre era a dona da verdade... o que eu pensava, o que eu dizia (...) (M.).

(...) eu era muito agressiva, eu era muito mandona, eu era dona da situação, devido àquele problema do marido ser assim (alcoolista), que eu tive que tomar a frente de tudo, eu me tornei muito mandona, sabe? Eu resolvia as coisas no grito e com o programa eu me reeduquei (...) (E.).

(...) eu era muito auto-suficiente e muito egocêntrico, eu me promovia a mim mesmo (...) eu era o centro e tudo, tudo quem tava em primeiro lugar era eu... (N.).

(...) hoje eu entrego totalmente a minha vida aos cuidados do Poder Superior, esse Deus que antes eu não acreditava mais... esse Deus que não me ajudava (...) na verdade eu queria me colocar no lugar dele... eu sou a criatura, ele é o criador, eu queria tá lá no lugar dele, eu queria resolver as coisas. Então, no momento que eu comecei a usar a humildade, me colocar no meu lugar de criatura (...) eu sinto que todos os meus defeitos de caráter estão sendo... substituídos por qualidades (...) eu tenho exercitado muito a fé, né, nesse Poder Superior (...) como uma filha, eu tenho ele como um pai. (R.).

Essa última transcrição oportuniza a reflexão sobre as dimensões da experiência religiosa, conforme a proposta de Martín-Baró (1998), e suas implicações na recuperação dos integrantes de N/A.

Segundo Martín-Baró (1998), a experiência religiosa transita numa dupla dimensão, correspondente aos dois elementos fundamentais das representações religiosas: a relação entre homem e Deus e a salvação.

- Verticalidade-horizontalidade: refere-se à relação entre Deus e o homem. Varia de uma concepção de Deus como ser superior, distante e inacessível, com o qual somente é possível se relacionar na forma de uma criatura diante de seu criador, uma relação vertical de submissão hierárquica, até 0 entendimento de Deus ainda como ser superior, contudo próximo e acessível, com o qual se pode estabelecer um relacionamento de respeitoso companheirismo, algo tipo um pai bondoso.

- Transcendentalidade-historicidade: alude à idéia de salvação. Alterna-se entre a salvação compreendida como ação meta-histórica de Deus, que intervém na marcha dos acontecimentos para estabelecer, milagrosamente, a devida ordem e a salvação na forma de movimento divino através dos homens, que, por isso, devem assumir a responsabilidade de transformar o mundo a partir da própria história. No primeiro caso, o homem pede e espera a salvação; no segundo, age, como desígnio de Deus, para salvar-se. 
Martín-Baró (1998) associa verticalidade com transcendentalidade e horizontalidade com historicidade.

Acima, R. diz que entrega sua vida aos cuidados do Poder Superior, poder este que, anteriormente, ela sentia distante. A seguir, R. conclui que estava tentando assumir o lugar de Deus, esquecendo-se de sua condição de criatura. Ao situar-se como criatura perante o criador, R. entra em harmonia com o Poder Superior, tal como uma filha com seu pai.

Pensando em termos da dupla dimensão de Martín-Baró (1998), nota-se a ruptura da polaridade entre a experiência vertical e a horizontal de relação com Deus.

Colocando-se na posição de criatura (relação vertical), R. sente-se mais próxima de Deus (Poder Superior), como uma filha próxima ao pai (relação horizontal). Reportando-se a sua situação anterior a N/A, R. entende que estava longe de Deus, justamente por querer tomar o lugar dEle, fazer o que somente Ele poderia fazer, "resolver as coisas" (relação transcendental), ou seja, um projeto mais próximo daquilo que Martín-Baró (1998) considera horizontal e histórico.

Depois de entrar em N/A, R. recuperou sua prática religiosa de acordo com os novos parâmetros que o grupo lhe apresentou: reconhecimento da própria impotência perante as emoções ( $1^{\circ}$ Passo), crença e entrega pessoal ao Poder Superior, que pode restaurar o bem-estar $\left(2^{\circ} \mathrm{e} 3^{\circ}\right.$ Passos $)$.

Após determinar um compromisso religioso vertical e transcendental, o programa dos Doze Passos dirige-se para a ação do praticante, através da realização do "inventário moral" (auto-análise para identificar e assumir os "defeitos" pessoais) e da admissão das próprias falhas perante Deus, si mesmo e outra pessoa $\left(4^{\circ} \mathrm{e} 5^{\circ}\right.$ Passos), abrindo, também, uma experiência religiosa histórica, cuja efetividade depende das atitudes do praticante.

Os passos 6 e 7 retomam - e reforçam - a religiosidade vertical-transcendente, enquanto o $8^{\circ}, 9^{\circ}$ e $10^{\circ}$ novamente deslocam a ênfase para a ação pessoal (religiosidade histórica). $\mathrm{O}$ passo 11 tende à verticalidade, e o 12 , à historicidade.

A religiosidade instaurada pelo programa dos Doze Passos é vertical no que diz respeito à relação com Deus, o Poder Superior, e inclina-se para a historicidade no que tange à salvação (cura). Entendese que a religiosidade não é totalmente histórica, porque à verticalidade está, necessariamente, associado um componente transcendental (vide passos 2,6 e 7), que a reforça.
A horizontalidade que R. vivencia em sua relação com Deus pode dever-se aos progressos pessoais que obteve a partir da crença num poder superior, de tal maneira que o bem-estar alcançado seja interpretado como recompensa e ratifique essa crença, a qual se torna mediadora de um sentimento de proximidade. É possível pensar: se Deus responde é porque está próximo.

Outros entrevistados também manifestam uma religiosidade vertical, vinculada a acontecimentos positivos e progressos pessoais:

(...) tamanha era a minha decadência emocional que eu tentei contra minha vida três vezes (...) e, graças ao Poder Superior, falhou... eu agradeço ao meu Poder Superior todos os dias, pelos 5 filhos que tive(...) homem eu não podia ver na minha frente, não era minha intenção casar, por isso que eu digo que existe um Poder Superior que traça as coisas, a gente faz um plano, e as coisas acontecem de outro(...). (E.).

As referências de E. ao Poder Superior encerram, também, uma religiosidade transcendental.

(...) eu era doente, porque eu não via um poder superior a mim (...) eu era o Poder Superior meu mesmo (...) (N.).

Essa verticalidade religiosa, no entanto, não obscurece o comprometimento pessoal dos entrevistados com sua recuperação (historicidade). Quando solicitados a avaliar o trabalho de N/A, destacaram a utilidade do programa, desde que a pessoa se dedique ativamente a sua prática.

A integração, a princípio contraditória, de uma experiência religiosa vertical e histórica, como ocorre em N/A, faz pensar na origem desse programa de recuperação com Alcoólicos Anônimos. Diferentemente de um problema emocional, em geral associado a idiossincrasias que dificultam uma formulação genérica de sua dinâmica, o alcoolismo apresenta-se na forma de comportamentos facilmente mapeáveis, em relação aos quais uma abordagem mais prescritiva e pragmática é necessária. É necessário parar de beber.

A transposição do programa de Alcoólicos Anônimos para N/A exigiu um recurso conceitual restritivo: na falta de um comportamento-padrão que definisse a "doença mental e emocional", adotou-se a idéia-base da doutrina cristã para defini-la como "Uma única doença, uma coisa só" (Neuróticos Anônimos, 1996/1969, p. 1), cujo modo de manifestação (idiossincrasias) é variável. $\mathrm{O}$ que um doente 
emocional deve parar? Deve parar o egoísmoegocentrismo.

Em se tratando de uma construção terapêutica sobre a doutrina cristã, a verticalidade da relação com Deus reforça o aspecto "curativo" do Poder Superior e garante o devido suporte para as inadiáveis iniciativas que o neurótico precisa tomar, a fim de recuperar-se. Tendo em vista o estado de debilitação que costuma acompanhar os sofredores de problemas emocionais, entende-se que a "prescrição" de fé num poder realmente superior funciona como um estratagema cognitivo que alavanca atitudes em pessoas com precária capacidade de mobilização.

Conforme Amatuzzi (1998), a pessoa religiosa age estimulada pelo sentimento da presença protetora de Deus, cuja resposta humana é a confiança da entrega. $\mathrm{O}$ autor mostra que, apesar de a experiência religiosa envolver entrega ou abandono pessoal ao poder de Deus, numa postura sugestiva de submissão, passividade e conformismo, ela se caracteriza por uma resposta ativa, na forma de enfrentamento de situações de um modo até inédito, sem que a pessoa, no entanto, deixe de atribuir seus sucessos à presença de Deus. A experiência dos informantes deste estudo segue a descrição do autor.

\section{CONCLUSÃO}

A experiência religiosa aqui considerada apresenta uma importante diferença em relação aos trabalhos mencionados acima: a experiência dos informantes inicia com uma procura por auxílio para dificuldades emocionais, o grupo ao qual se dirigem é para "neuróticos". O que encontraram lá, no entanto, foi uma adaptação de princípios cristãos para uma suposta "doença emocional" que se caracteriza precisamente pelo distanciamento desses princípios. Sendo assim, a experiência religiosa se confunde com a recuperação emocional. Somente há experiência religiosa à medida que a pessoa se vincula ao grupo, e essa vinculação indica progresso na superação do problema pessoal. É difícil distinguir o que é experiência religiosa do que é processo de recuperação.

Pode-se retomar a afirmação de Pargament (citado em Paiva, 1998) citada acima: a religião apresenta uma flexibilidade muito grande para prover seus adeptos de meios e fins. N/A não é religião, é justamente um exemplo desse alcance da doutrina religiosa. A entrega pessoal por meio de crença e compromisso religioso relatada pelos entrevistados permite pensar que, sem ela, uma pessoa que se dirija a N/A dificilmente vivenciará os progressos relatados pelos participantes desta pesquisa. Um ilustrativo trecho de entrevista para finalizar o artigo:

(...) eu acho que o N/A, se não conduz a uma religião, ele conduz a você acreditar (...) a se espiritualizar, que o programa é totalmente espiritual (...) você acredita num Poder Superior, que é Deus como cada um O concebe... E através disso (...) muitas pessoas, elas acabam indo pra uma religião (A.).

\section{REFERÊNCIAS}

Amatuzzi, M. M. (1998). A experiência religiosa: estudando depoimentos. Estudos de Psicologia, 15(2), 3-27.

Argyle, M. (1993). The social psychology of everyday life. London: Routledge.

As leis da doença mental e emocional (1996). São Paulo: ENABRA

Back, K. W. \& Taylor, R. C. (1976). Self-help groups: tool or symbol? The Journal of Applied Behavioral Science, 12, 295-309.

Bergin, A. E.; Stinchfield, R.; Gaskin, T.; Masters, K. \& Sullivan, C. (1988). Religious life-styles and mental health: An exploratory study. Journal of Counseling Psychology, 35(1), 91-98.

Bergin, A. E. (1991). Values and religious issues in psychotherapy and mental health. American Psychologist, 46(4), 394-403.

Bíblia de Jerusalém. (1985). N. T. Evangelho de São Mateus (pp. 1837-1896). Português. São Paulo: Edições Paulinas.

Bíblia de Jerusalém. (1985). N. T. Primeira Epístola de São João (pp. 2282-2293). Português. São Paulo: Edições Paulinas.

Borkman, T. (1976). Experiential knowledge: a new concept for the analysis of self-help groups. Social Service Revie, 50, 446-454.

De Mari, J.; Teich, D. H.; Nogueira, P.; Camargos D. \& Pimentel, M. (1999, 24 de fevereiro). A luta contra o vício: como funcionam os grupos anônimos que ajudam as pessoas a se livrar da dependência. Veja, 8.

Dumont, M. P. (1974). Self-help treatment programs. American Journal of Psychiatry, 131, 631-635.

Hill, P. C. (1999). Giving religion away: What the study of religion gives psychology. The International Journal for the Psychology of Religion, 9(4), 229-249.

Jacobs, M. \& Goodman, G. (1989). Psychology and self-help groups. American Psychologist, 44, 536-545.

Larson, D. B. (1992). Associations between dimensions of religious commitment and mental health reported in the American Journal of Psychiatry and Archives of General Psychiatry: 1978-1989. American Journal of Psychiatry, 149(4) 557-559.

Levy, L.H. (1976). Self-help groups: types and psychological processes. Journal of Applied Behavioral Science, 12, 310-322.

Martins, M. C. (1979). Em busca de uma compreensão do trabalho terapêutico dos Alcoólicos Anônimos. Arquivos da Clínica Pinel, 5(4), 271-277.

Martín-Baró, I. (1998). Psicología de la liberación. Madrid: Trotta S. A. 
McCullough, M. (1995). Prayer and health: conceptual issues, research review, and research agenda. Journal of Psychology and Theology, 23(1), 15-29.

Miller, W. \& Thorensen, C. (2003). Spirituality, religion, and health: an emerging research field. American Psychologist, 58(1), 24-35.

Neuróticos Anônimos. (1996). A doença emocional é doença espiritual. Em As leis da doença mental e emocional ( pp.13-17). São Paulo: ENABRA. (Trabalho original publicado em 1966)

Neuróticos Anônimos. (1969). As leis da doença mental e emocional. In As leis da doença mental e emocional (pp. 1-8). São Paulo: ENABRA.

Neuróticos Anônimos. Folheto, s/d.

Neuróticos Anônimos. Livreto, s/d.

Paiva, G. J. de (1998). AIDS, psicologia e religião: o estado da questão na literatura psicológica. Psicologia: Teoria e Pesquisa, 14(1), 27-34.

Paloutzian, R. F. (1996). Invitation to the Psychology of Religion. Boston: Allyn \& Bacon.

Roehe, M. V. (2000). Do desabafo à mensagem: vivência de recuperação em Neuróticos Anônimos. Dissertação de Mestrado
Não-Publicada., Faculdade de Psicologia, Pontifícia Universidade Católica do Rio Grande do Sul. Porto Alegre.

Rootes, L. \& Aanes, D.(1992). A conceptual framework for understanding self-help groups. Hospital and Community Psychiatry, 43(4), 379-381.

Sanchez Vidal, A. (1991). Psicologia comunitária: bases conceptuales y organizativas, métodos de intervención. Barcelona: PPU.

Seminério, F. (1998). A religião como fenômeno psicológico. Temas em Psicologia, 6(2), 161-172.

Vattano, A. (1972). Power to the people: Self-help groups. Social Work, 17, 7-15.

\section{ANEXO}

\section{Os Doze Passos de N/A}

1 - Admitimos que éramos impotentes perante nossas emoções - que tínhamos perdido o domínio sobre nossas vidas.

2 - Viemos a acreditar que um Poder superior a nós mesmos poderia devolver-nos à sanidade.

3 - Decidimos entregar nossa vontade e nossa vida aos cuidados de Deus, na forma em que o concebíamos.

4 - Fizemos minucioso e destemido inventário moral de nós mesmos.

5 - Admitimos perante Deus, perante nós mesmos e perante outro ser humano a natureza exata de nossas falhas.

6 - Prontificamo-nos inteiramente a deixar que Deus removesse todos esses defeitos de caráter.

7 - Humildemente rogamos a Ele que nos livrasse de nossas imperfeições.

8 - Fizemos uma relação de todas as pessoas que tínhamos prejudicado e nos dispusemos a reparar os danos a elas causados.

9 - Fizemos reparações diretas dos danos causados a tais pessoas, sempre que possível, salvo quando fazê-lo significasse prejudicá-las ou a outrem.

10 - Continuamos fazendo o inventário pessoal e, quando estávamos errados, nos o admitíamos prontamente.

11 - Procuramos, através da prece e da meditação, melhorar nosso contrato consciente com Deus, na forma em que o concebíamos, rogando apenas o conhecimento de Sua vontade em relação a nós e forças para realizar essa vontade.

12 - Tendo experimentado um despertar espiritual graças a estes passos, procuramos transmitir essa mensagem aos neuróticos e praticar esses princípios a todas nossas atividades.

Endereço para correspondência: Marcelo Vial Roehe: Rua Caiapó, 120, CEP 91900-550. Porto Alegre-RS. E-mail: mvroehe@ibest.com.br 